\title{
Improvement of recovery parameters using patient-controlled epidural analgesia after oncological surgery. A prospective, randomized single center study*
}

Armeana Olimpia Zgâia ${ }^{1,2}$, Cosmin Ioan Lisencu ${ }^{1,2}$, Alexandru Rogobete ${ }^{3}$, Cătălin Vlad ${ }^{1,2}$, Patriciu AchimaşCadariu $^{1,2}$, Gabriel Lazăr ${ }^{1,2}$, Maximilian Muntean ${ }^{1,2}$, Florin Ignat ${ }^{1,2}$, Vlad Ormindean ${ }^{2}$, Alexandru Irimie ${ }^{1,2}$

${ }^{1}$ Department of Surgery, Ion Chiricuta Oncology Institute, Cluj-Napoca, Romania

${ }^{2}$ Iuliu Hatieganu University of Medicine and Pharmacy, Cluj-Napoca, Romania

${ }^{3}$ Victor Babes University of Medicine and Pharmacy, Timisoara, Romania

\begin{abstract}
Purpose: The aim of this study was to compare patient-controlled epidural analgesia (PCEA) versus conventional opioid intravenous (IV) infusion after gastrointestinal cancer surgery regarding several postsurgery parameters of recovery.

Methods: One hundred and one patients were prospectively randomized to receive either thoracic/ lumbar PCEA (PCEA group) or the standard analgesia technique used in our hospital, conventional IV infusion of morphine (IVMO group) after gastrointestinal cancer surgery. Pain intensity, time of mobilization and bowel function recovery were analyzed post-surgery. We also evaluated postoperative complications and length of Postoperative-Intermediate Intensive Care Unit (PI-ICU) stay and hospital stay.

Results: Pain intensity was significantly less in the PCEA group in comparison with the IVMO Group at awakening 2, 8, 24, 30 and 48 hours after surgery $(\mathrm{p}<0.001, \mathrm{p}<0.001, \mathrm{p}<0.001, \mathrm{p}=0.043, \mathrm{p}=0.036$, and $\mathrm{p}=0.029$, respectively). The latency to bedside mobilization, walking, first postoperative flatus and apparition of first stool were significantly faster ( 1.74 versus 2.26 days, 3.06 versus 3.78 days, 2.1 versus 3.14 days and 3.73 versus 5.28 days, respectively) in the PCEA group than in the IVMO group ( $<<0.001, p<0.001$, $\mathrm{p}<0.001$, and $\mathrm{p}<0.001$, respectively). The incidence of nausea/vomiting was significantly lower in the PCEA group in comparison with the IVMO group $(p=0.001)$. Surgical-associated complications were significantly lower in the IVMO Group than in the PCEA group $(p=0.023)$. Length of PI-ICU stay was similar in the two groups but length of hospital stay was significantly shorter in PCEA group (4 versus 5 days $p=0.2849,9$ versus 12 days; $p<0.001$ ).

Conclusions: PCEA provides better postoperative pain control, improves postoperative recovery after gastrointestinal cancer surgery compared with conventional intravenous morphine infusion. Therefore, it is more acceptable than conventional pain management.
\end{abstract}

Keywords: gastrointestinal cancer surgery, patient-controlled epidural analgesia, postoperative analgesia

Received: 23 March 2017 / Accepted: 31 March 2017

Rom J Anaesth Int Care 2017; 24: 29-36

\section{Introduction}

Colorectal cancer is the third most common cancer in men $(10 \%)$ and the second (9.2\%) in women [1]. Also, gastric cancer is the fifth most common malig-

\begin{tabular}{ll}
\hline Address for correspondence: & Dr. Cosmin Ioan Lisencu \\
& Department of Surgery \\
& Ion Chiricuta Oncology Institute \\
& $34-36$ Republicii Street \\
& 400015 , Cluj-Napoca, Romania \\
& E-mail: drilisencu@yahoo.com
\end{tabular}

nancy in both sexes worldwide [1]. Surgery represents the cornerstone in the management of solid malignant tumors but it is associated with high incidence of postoperative complaints and complications [2-4]. Acute postoperative pain, nausea and vomiting, delay in gastrointestinal motility and mobilization have all been associated with reduced early postoperative well-being and prolonged hospitalization [5-7]. The provision of good symptom relief following gastrointestinal cancer surgery is important for limiting morbidity and mortality $[8,9]$. Intravenous patient-controlled analgesia (IV

\footnotetext{
* The abstract of this article was accepted to be presented at ESA 2017, Geneva, Switzerland (Poster Session-Pain)
} 
PCA) has been considered the optimal methods for pain treatment after major laparotomy, but intravenous continuous morphine analgesia (IVMO) is still the most commonly used technique in our department $[10,11]$. Patient-controlled epidural analgesia (PCEA) decreases the stress response after surgery, provides a good postoperative pain control but controversies still exist about its effects on the patient's outcome after abdominal surgery [3, 7, 12 -15]. The principal aim of this study was to compare the effects of PCEA and IVCA on postoperative morbidity, especially on pain, gastro-intestinal function recovery and capacity of selfmobilization for patients undergoing digestive cancer surgery. Another aim of our study was to evaluate the influence of the analgesia type on postoperative complications, length of postoperative intermediate intensive care unit (PI-ICU) stay and length of hospital stay.

\section{Methods}

The study was performed in the Department of Surgery of the Ion Chiricuta Oncology Institute ClujNapoca (IOCN), Romania, between February 2015 and November 2016. The ethical approval for this study was provided by the Ethical Committee of the IOCN (n 3327/22.04.2013). Written informed consent was obtained from all patients before the inclusion in the study.

\section{Participants}

A prospective study of patients undergoing gastrointestinal surgery for cancer under general anaesthesia was designed with a random allocation of postoperative analgesia to either PCEA or IVMO for a period of 48 hours after surgery. Inclusion criteria were: all patients undergoing elective surgery for gastro-intestinal cancer, with physical status I, II or III accordingly with American Society of Anesthesiologists Physical Status Classification System (ASA) and age greater than 18 years. Exclusion criteria were: emergency surgical interventions, contraindication to the epidural catheter placement, such as local skin infection, genetic or acquired coagulopathy, permanent neurologic sequels of the legs, prior lumbar spine surgery, patients who were not able to use the PCEA technique, patient's refusal and drugs allergies (opioids, paracetamol, nonsteroidal anti-inflammatory drugs (NSAIDs), and local anaesthetics).

\section{Outcomes}

The main outcome of this study was postoperative pain intensity. The secondary outcomes were the time of bedside mobilization and walking, first postoperative flatus, first postoperative stool postoperative complications (respiratory, cardiovascular, digestive and surgical associated complications), length of ICU and hospital stay.

\section{Clinical Scores}

Numerical Rating Scale (NRS) is a good, quick and easy tool for the evaluation of pain intensity in postsurgery settings $[16,17]$. This is a 11-point numeric scale ranging from ' 0 ' representing "no pain" to ' 10 ' representing "unbearable pain" and the patients have to choose a whole number $(0-10$ integers $)$ that best reflects the severity of pain [16-18].

\section{Clinical and demographical measurements}

The preoperative demographic and clinical data were collected from the medical charts: sex, age, body mass index (BMI), demographic area, pathology, chronic treatment, anaesthesiological risk. The intraoperative variables were recorded from the anaesthesia charts: total intraoperative opioid consumption and the surgery time defined as the time from the skin incision until anaesthesia was discontinued. Postoperative pain intensity was assessed immediately after arrival in the ICU, at 2, 8, 12 and 24 hours in the day of surgery and every 6 hours in the first day after surgery, for a period of 48 hours post-surgery. Pain severity was assessed using NRS by the anaesthesiologists and by the nurses from PI-ICU. The post-surgery variables were obtained from the medical charts. We evaluated the time of bedside mobilization defined as the number of days elapsed after surgery until the patients were able to mobilize bedside and walk in the ward, respectively; the time of the first postoperative flatus and of the first defecation. Also, we assessed postoperative complications such as respiratory, cardiovascular, digestive and surgical complications. The length of PI- ICU stay and respectively, the length of hospital stay, defined as days of PI-ICU admission and respectively, days of hospital admission, were also evaluated.

\section{Study procedure}

The patients were randomly assigned to either Patient Controlled-Epidural Analgesia Group (PCEA group) or to Intravenous Morphine Analgesia Group (IVMO group). An external clinical researcher was designed for the patient's allocation, using online software for randomization [19]. Before surgery, the researcher and the anaesthesiologists had explained and instructed the patients regarding the use of NRS for assessing the postoperative acute pain. Also, the patients included in the PCEA group were instructed about the patient-controlled analgesia technique. All the operations were performed by experienced surgeons following the local surgery protocol, under the same protocol of general inhalational anaesthesia, with neuromuscular block as standard. In the PCEA group, an epidural catheter was placed under standard monitoring, before induction of general anaesthesia. The epidural catheter was inserted at a level ranging from T8 to L2, depending on the surgery type and level of surgical incision. Intravascular and subarachnoid 
placement of the catheter was ruled out with a testdose of $3 \mathrm{ml}$ of $1 \%$ lidocaine with adrenaline. Thirty minutes before the end of surgery the patients from the PCEA group received 5-7 $\mathrm{mL}$ of mixture of $0.3 \%$ ropivacaine through the epidural catheter and patients from IVMO Group received $100 \mathrm{mg}$ ketoprofen intravenously and $5 \mathrm{mg}$ of morphine (IV). After surgery, all the patients were transferred to the PIICU. Postoperative analgesia consisted of ketoprofen $100 \mathrm{mg}$, IV every 8 hours and paracetamol $1 \mathrm{~g}$ IV every 6 hours for all the patients in both groups. In the PCEA group an epidural mixture of ropivacaine and fentanyl was administered as follows: during the first 24 hours after surgery, $0.3 \%$ ropivacaine and $2 \mu \mathrm{g} / \mathrm{mL}$ fentanyl which was lowered during the second day to $0.2 \%$ ropivacaine and $2 \mu \mathrm{g} / \mathrm{mL}$ fentanyl. The PCEA regimen was $5-7 \mathrm{ml} / \mathrm{h}$ basal rate and $5-7 \mathrm{~mL}$ bolus as request with a lock-out period of $20 \mathrm{~min}$. The patients from IVMO group received IV continuous infusion of morphine: $2 \mathrm{mg} / \mathrm{h}$ as basal infusion and 3-5 $\mathrm{mg}$ IV bolus administration every time when required in order to obtain NRS below 3/10. Vital signs and NRS for pain assessment were registered accordingly to local protocol for all the patients. In the patients with epidural catheter the motor block was evaluated using the Modified Bromage Score until the catheter was removed (after 48 hours for colon and rectum surgery postoperatively and 72 hours for gastric surgery postoperatively). Sedation and respiratory depression were recorded for the patients who received intravenous morphine. Postoperative variables were assessed by nurses and anaesthesiologists involved in the study. Postoperative management of the patients and the treatment of post-surgery complications were performed by the anaesthesiologist and surgeon team, coordinated by the study researcher.

\section{Statistical analyses}

The sample size was calculated for a primary outcome of NRS after surgery, considering a difference of 1 between groups as being clinically meaningful. We estimated this for a comparison made with a t-test for independent samples, with $95 \%$ power, a level of significance of 0.05 , a bidirectional $\mathrm{p}$ value, and equal sample sizes in the compared groups. We identified a standard deviation of 1.36 in a previous study as a base of variability in our calculations [20]. A sample size of 45 subjects per group was found, and we increased it to 50 to allow for loss to follow up. Categorical data were presented as counts and percentages. Continuous data were presented as mean and standard deviation for normally distributed data, or by median and quartiles for data not following the normal distribution, and graphically as box plots. The relation between two categorical variables was assessed with the chi-square test or the Fisher exact test. Comparison between the two treatments groups were performed with the independent t-test, for normally distributed data and the Wilcoxon rank sum test for data not following the normal distribution. For all statistical tests we used a 0.05 level of significance and the two tailed $p$ value. We used the $\mathrm{R}$ environment for statistical computing and graphics version 3.2.3 [21].

\section{Results}

\section{Patient characteristics}

A total of 127 consecutive patients were screened and 26 patients were excluded due to refusal of study enrolment (19 patients) and because they did not meet inclusion criteria (7 patients: 5 - NSAIDs allergies, 2 - previous spine surgery). Also, one patient from PCEA was excluded during the study because he died 24 hours after surgery secondary to hemorrhagic shock (Figure 1). One hundred and one patients fulfilled the inclusion criteria and consented to the study. Fifty-one patients were assigned to the PCEA group and 50 patients were enrolled to the IVMO group. One patient from PCEA group died because of postoperative complications before the end of study evaluation and was excluded from the analyses.

Fifty patients from each group completed the study (Figure 1). We did not identify significant statistically differences between the two groups regarding the age, gender, body mass index (BMI), associated pathology, chronic treatment and anaesthetic risk score ASA. The surgery time was significantly longer and intraoperative opioid consumption was significantly higher in the PCEA group as compared to the IVMO group (Table 1).

\section{Postoperative pain scores}

Patients receiving PCEA experienced less pain after surgery than IVMO group patients, especially during the first 8 hours after surgery. More specifically, postoperative NRS pain scores were lower in the PCEA group compared to IVMO group, as follows: immediately after awakening median (IQR) NRS 0 (0-3.75) versus 7 (5-8); $\mathrm{p}<0.001$, at 2 hours median (IQR) 0 (0-4) versus 6 (4-6.75); $\mathrm{p}<0.001$, at 8 hours median (IQR) $0(0-1.75)$ versus $3(1-4.75) ; \mathrm{p}<0.001$, at 24 hours median (IQR) $0(0-1.75)$ versus $1(0-3) ; \mathrm{p}<0.045$, at 30 hours median (IQR) $0(0-1)$ versus $1(0-2.75)$; $p$ $=0.017$ and at 48 hours the median (IQR) $0(0-0)$ versus $0(0-0) ; p=0.034$. Pain intensity was similar in the two groups at $12(\mathrm{p}=0.067)$ and $36(\mathrm{p}=0.514)$ hours after surgery (Figure 2, Table 2).

\section{Indices of clinical postoperative outcome}

The first postoperative flatus and first stool were noticed significantly earlier in the PCEA Group compared with IVMO Group ( $<<0.001)$. The PCEA group also showed a significantly shorter time to 


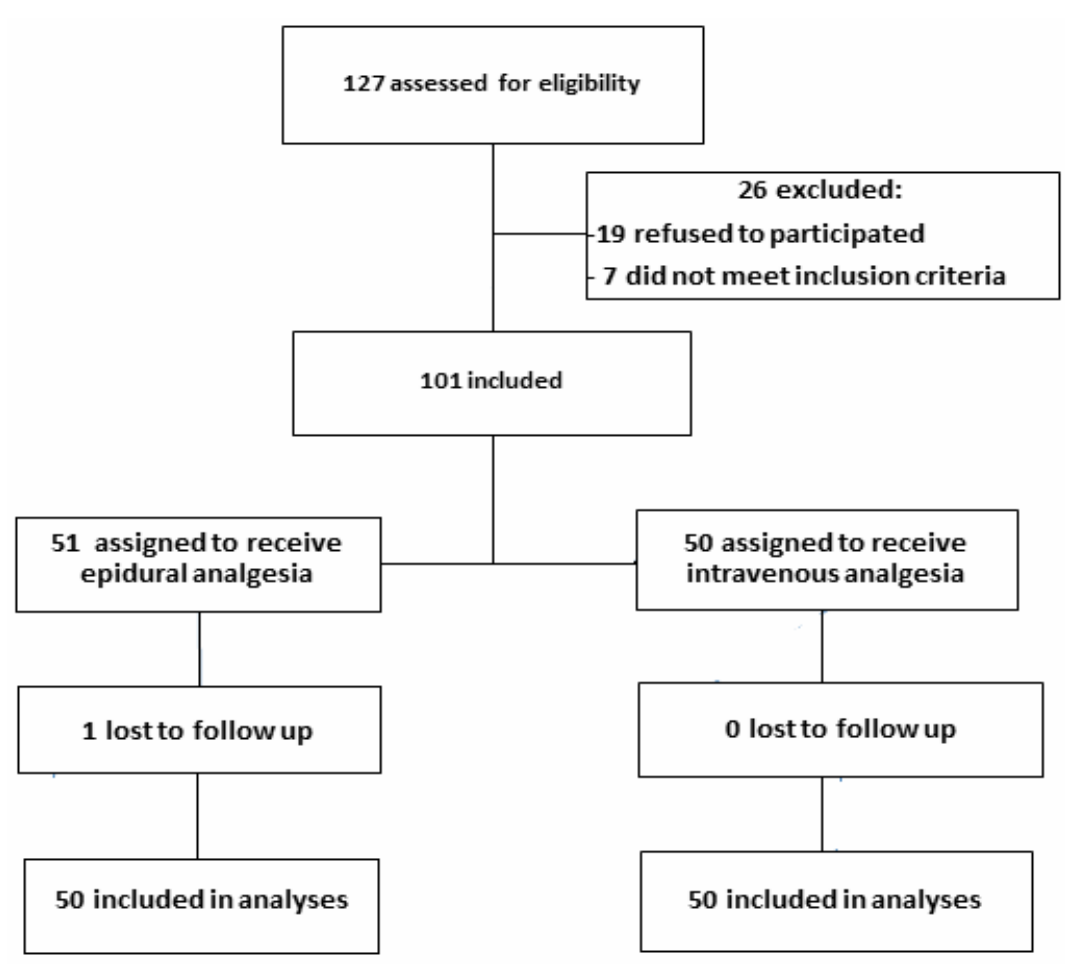

Fig. 1. Study flow diagram

Table 1. Clinical and demographic data

\begin{tabular}{|c|c|c|c|}
\hline & $\begin{array}{l}\text { IVMO group } \\
(\mathrm{n}=50)\end{array}$ & $\begin{array}{l}\text { PCEA group } \\
(\mathrm{n}=50)\end{array}$ & p-value \\
\hline $\operatorname{Sex}(M), n(\%)$ & $32(64)$ & $33(66)$ & 0.834 \\
\hline Age (years), mean (SD) & $64.8(9.3)$ & $60.76(11.13)$ & 0.052 \\
\hline BMI $\left(\mathrm{kg} / \mathrm{m}^{2}\right)$, mean $(\mathrm{SD})$ & $28.73(4.75)$ & $28.53(5.13)$ & 0.836 \\
\hline Associated pathology n (\%) & $37(74)$ & $39(78)$ & 0.64 \\
\hline Chronic treatment n (\%) & $34(68)$ & $26(52)$ & 0.102 \\
\hline Anaesthesiological risk (ASA) n (\%) & $\begin{array}{l}19: 9(18) \\
29: 37(74) \\
39: 4(8)\end{array}$ & $\begin{array}{l}19: 5(10) \\
29: 45(90) \\
39: 0(0)\end{array}$ & 0.053 \\
\hline Surgery time (min) median (IQR) & $122.5(110-143.75)$ & $143.5(130-180)$ & $<0.001$ \\
\hline Intraoperative opioid consumption (mg) median (IQR) & $0.3(0.2-0.3)$ & $0.3(0.26-0.35)$ & 0.012 \\
\hline
\end{tabular}

$\mathrm{SD}=$ standard deviation, $\mathrm{IQR}=$ quartiles, statistical significance if $\mathrm{p}$-value $<0.05$

Table 2. Mean acute postoperative pain scores (NRS) at different times

\begin{tabular}{llll}
$\begin{array}{l}\text { After surgery time } \\
\text { (hours) }\end{array}$ & $\begin{array}{l}\text { IVMO group } \\
(\mathrm{n}=50) \\
\text { median (IQR) }\end{array}$ & $\begin{array}{l}\text { PCEA group } \\
(\mathrm{n}=50) \\
\text { median (IQR) }\end{array}$ & p-value \\
\hline 0 & $7(5-8)$ & $0(0-3.75)$ & $<0.001$ \\
2 & $6(4-6.75)$ & $0(0-4)$ & $<0.001$ \\
\hline 8 & $3(1-4.75)$ & $0(0-1.75)$ & $<0.001$ \\
12 & $1(0-3)$ & $0(0-2)$ & 0.067 \\
24 & $1(0-3)$ & $0(0-1.75)$ & 0.045 \\
30 & $1(0-2.75)$ & $0(0-1)$ & 0.017 \\
36 & $0(0-2)$ & $0(0-1)$ & 0.514 \\
48 & $0(0-0)$ & $0(0-0)$ & 0.034 \\
\hline
\end{tabular}

$\mathrm{IQR}=$ quartiles; statistical significance if $\mathrm{p}$-value $<0.05$ 


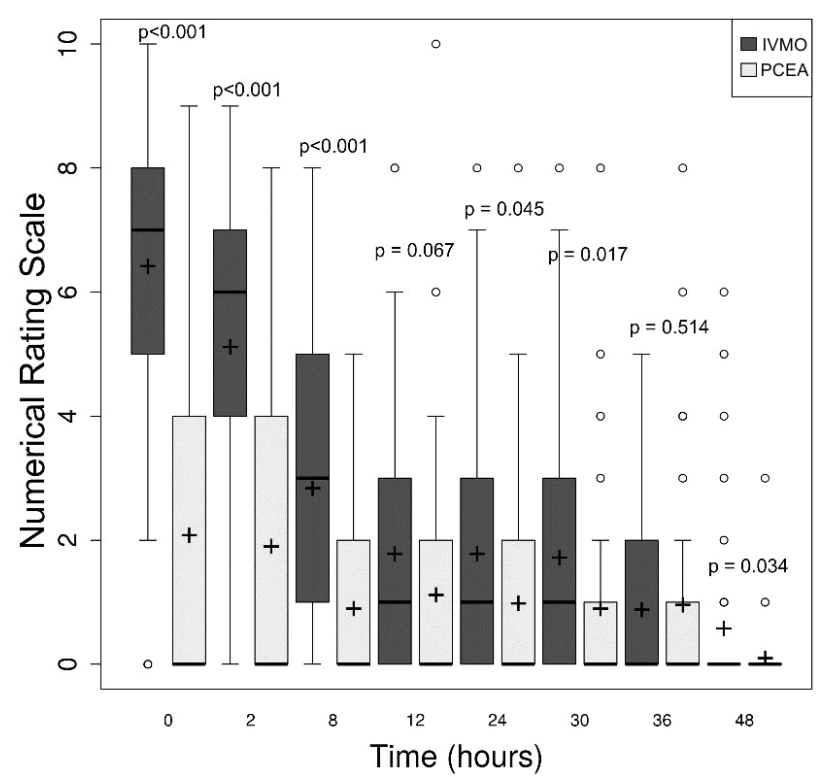

Fig. 2. Pain evolution in time. The + sign represents the mean, the circles the outliers, while the boxes the median and the interquartile range

bedside mobilization and walking as compared to the IVMO group ( $\mathrm{p}<0.001)$ (Table 3 ).

Nausea and vomiting were significantly less frequent in the PCEA group (16.33\%) IVMO Group (66\%) in comparison with the IVMO group $(66 \%)(\mathrm{p}<0.001)$ (Table 3).
Surgery-related complications, such as enteral fistula and wound infections, were more frequent in the PCEA group than in the IVMO group but the difference was not statistically significant $(\mathrm{p}=0.023)$ (Table 3 and 4$)$. One patient from each group died from intra-abdominal infectious complications, after more than 48 hours postsurgery.

There were no significant differences regarding respiratory and cardiovascular complications between the groups. We did not identify serious adverse events related to the analgesia technique. The ICU length of stay was similar in the two groups of patients $(\mathrm{p}=$ 0.284 ). However, the length of hospital stay was significantly shorter in the PCEA group ( $9 \pm 2$ days) than in the IVMO group $(12 \pm 3$ days) $(p<0.001)$ (Table 3$)$.

\section{Discussion}

Despite progress in understanding pain physiopathology and improved analgesia techniques, pain remains the most common and frightening problem after surgery. Good pain relief after surgery is achieved in only $25 \%$ of the patients [9]. Moreover, it was demonstrated that insufficient pain control is associated with negative postoperative outcomes such us delay in mobilization and bowel function recovery, cardiovascular and respiratory complications and prolonged hospital stay [7, 8, 22, 23]. Consequently, an optimal pain control is mandatory after surgery. The studies

Table 3. Indices of clinical postoperative outcome

\begin{tabular}{|lllr}
\hline & $\begin{array}{l}\text { IVMO group } \\
(\mathrm{n}=50)\end{array}$ & $\begin{array}{l}\text { PCEA group } \\
(\mathrm{n}=50)\end{array}$ & p-value \\
\hline Bedside mobilization (day after surgery), mean (SD) & $2.26(0.56)$ & $1.74(0.49)$ & $<0.001$ \\
\hline Walking (days after surgery), mean (SD) & $3.78(0.76)$ & $3.06(0.62)$ & $<0.001$ \\
\hline Time to first postoperative flatus (day), mean (SD) & $3.14(0.64)$ & $2.1(0.81)$ & $<0.001$ \\
\hline Time to defecation (day), mean (SD) & $5.28(0.67)$ & $3.73(0.88)$ & $<0.001$ \\
\hline Respiratory complications (bronchopneumonia) $\mathrm{n}(\%)$ & $1(2)$ & $3(6.12)$ & 0.362 \\
\hline Cardiovascular complications (bradycardia) $\mathrm{n}(\%)$ & $2(4)$ & $0(0)$ & 0.495 \\
\hline Nausea, vomiting n (\%) & $33(66)$ & $8(16.33)$ & $<0.001$ \\
\hline Surgery-associated complications $\mathrm{n}(\%)$ & $2(4)$ & $9(18.37)$ & 0.023 \\
\hline PI-ICU length of stay, median (IQR) & $4(3-5)$ & $5(4-5)$ & 0.284 \\
\hline Hospital length of stay, median (IQR) & $12(10-13.75)$ & $9(8-11)$ & $<0.001$ \\
\hline
\end{tabular}

$\mathrm{SD}=$ standard deviation, $\mathrm{IQR}=$ quartiles, statistical significance if $\mathrm{p}$-value $<0.05$

Table 4. Surgery-associated complications

\begin{tabular}{lccc|}
\hline Category & $\begin{array}{c}\text { IVMO Group } \\
\mathrm{n}=2\end{array}$ & $\begin{array}{c}\text { PCEA Group } \\
\mathrm{n}=9\end{array}$ & $\begin{array}{c}\text { Total } \\
\mathrm{n}=11\end{array}$ \\
\hline Enteral fistula, $\mathrm{n}(\%)$ & $1(2)$ & $4(8)$ & $5(5)$ \\
Incisional hernia, $\mathrm{n}(\%)$ & $1(2)$ & $1(2)$ & $2(2)$ \\
Wound infections, $\mathrm{n}(\%)$ & 0 & $4(8)$ & $4(4)$ \\
\hline
\end{tabular}


reported that epidural analgesia is superior to intravenous opioid analgesia in patients undergoing major thoracic, abdominal and pelvic surgery, including colorectal and gastric cancer surgery $[3,6,7,10,11,13$, $15,24]$. PCA is an effective and safe method for pain relief after major, open, abdominal surgery $[10-15,24$, 25]. PCEA analgesia is an important tool of anaesthetists assuring a good pain control, a decrease of several postoperative complications and thus improving safety and early well-being of the patients after surgery $[25,26]$. Our finding of improved postoperative pain scores by PCEA is in concordance with previous reports in pelvis and abdominal surgery $[3,6,7,10,11$, $15,24,26,27]$. We noticed a significantly prolonged surgery time in the PCEA group. This may imply that the postoperative pain and analgesic needs in patients from the PCEA Group might have been expected to be higher, which was not the case in our study. On the contrary, we obtained better pain scores in the PCEA Group, further sustaining the superiority of epidural analgesia after major abdominal surgery. Inadequate pain relief may negatively affect postoperative mobilization. Our results showed that the PCEA is associated with early postoperative mobilization. Gastrointestinal paralysis is common after abdominal surgery and is caused by the inflammatory cascade secondary to the stress response to surgery [28]. Prolonged postoperative ileus is associated with prolonged hospitalization and increased costs [7, 23, 24, 29]. The time to first postoperative flatus and stool commonly defines the gastrointestinal function recovery post-surgery and is generally chosen as an outcome measure in clinical studies assessing rehabilitation after surgery $[6,29]$. We demonstrated the effectiveness of epidural analgesia on the early returning of gastrointestinal transit after major open laparotomy. The majority of studies founded similar results. Guay et al. concluded that epidural analgesia accelerates the recovery of gastrointestinal transit after open abdominal surgery [6]. Also, Carli et al. founded that thoracic epidural analgesia shortens the duration of postoperative ileus after colorectal surgery as compared with PCA with IV morphine [30]. Moreover, Liu et al. founded that PCEA is associated with a quicker return of bowel activity as compared with PC with IV morphine [31]. As opposed to this, Rimaitis et al. could not find an improvement in bowel function after colorectal cancer when epidural analgesia was compared with intravenous opioid administration [32]. The incidence of postoperative nausea and vomiting varies between $20-30 \%$ and up to $80 \%$ in high-risk patients, following surgery under general inhalational anaesthesia $[32,34]$. We demonstrated a notably increased incidence of nausea and vomiting associated with IVMO. However, Rimaitis et al. did not find any difference regarding nausea and vomiting after colorectal cancer surgery when comparing epidural analgesia with systemic opioid analgesia [3].

Patients undergoing major abdominal and thoracic surgery are at an increased risk of various types of complications but studies suggest that epidural analgesia can decrease the incidence of respiratory, cardiovascular, infectious and thromboembolic complications [3537]. Epidural analgesia may ameliorate tissue oxygenation and pulmonary function by decreasing pain, sedation scores and improved diaphragmatic function $[38,39]$. Interestingly, in our study, we noticed an increased incidence of respiratory complications (bronchopneumonia) in patients who received epidural analgesia, although not statistically significant. This may be secondary to the low incidence of respiratory complications in our study.

Epidural analgesia is usually associated with cardiovascular complications such as hypotension but we did not identify this complication in the PCEA group [20, $35]$. We found a greater incidence of fistula in patients who received epidural analgesia but the difference was not statistically significant due to the very low incidence. Controversies still exist about this topic. Some studies have found an increased incidence of anastomotic leakage in patients receiving epidural analgesia after abdominal surgery; it was suggested that fluid administration for the treatment of hypotension secondary to epidural analgesia may be responsible for sutures edema and secondary dehiscence $[3,6]$. In our study the administration of extra fluid was not necessary because hypotension was not present in our patients. However, other studies reported that there is no difference in the incidence of this complication after abdominal surgery regardless of the analgesia type [40].

The length of PI-ICU and hospital stay may reflect the quality of postoperative recovery. Discharge from PI-ICU and from hospital may be influenced by many factors including medical decisions, expectance of patients, and socio-economic factors [41]. In our study, the analgesic modality did not influence the length of stay in the PI-ICU but we found a significant decrease of the length of the hospital stay for the patients receiving PCEA. The return of gastrointestinal function represents an important objective after abdominal surgery and a prerequisite with respect to hospital discharge [7]. The shorter length of hospital stay in the PCEA group can be explained by the faster returning of the intestinal transit and possibly with faster mobilization. In a study of 100 patients with colorectal surgery, Rimaitis et al. could not find any influence of epidural analgesia on the length of the hospital stay [3].

Some tendency of increased surgical complications and especially enteral fistulas with enteral fluid leakage may raise some questions about the safety of the epi- 
dural technique but other factors may be responsible for this, such as the longer surgery time in this group. The results of our study reveal some advantages but also risks associated with PCEA. Consequently, PCEA has to be used balancing benefits and potential sideeffects and complications on a case by case basis. One limitation of our study is that we compared two different and unblended analgesia techniques which may have caused some bias in data collection. The patient-controlled epidural technique was compared with a continuous morphine infusion analgesia; morphine given also as PCA would have been a more fair comparison, but we compared PCEA with the standard analgesia technique used in our hospital.

In conclusion, we report our results of two series of patients whose postoperative pain was treated by either PCEA or IVMO after digestive tract cancer surgery. The severity of acute pain was significantly reduced for the first 48 hours after surgery in patients who benefited from PCEA. Also, PCEA was associated with fewer nausea and vomiting episodes, earlier gastrointestinal function recovery, postoperative mobilization and reduced length of hospital stay. Surgery-associated complications were more frequent after PCEA.

\section{Conflict of interest}

Nothing to declare

\section{Acknowledgements}

This study was performed under the framework of the European Social Fund, Human Resources Development Operational Program 2007-2013, project no POSDRU/159/ $1.5 / 138776$

\section{References}

1. International Agency for Research on Cancer, World Health Organization. GLOBOCAN 2012: Estimated Cancer Incidence, Mortality and Prevalence Worldwide in 2012 [online]. [2013?] [cited 2017 January 11]. Available from: URL: http:// globocan.iarc.fr/

2. Smyth EC, Verheij M, Allum W, Cunningham D, Cervantes A, Arnold D, et al. Gastric cancer: ESMO Clinical Practice Guidelines for diagnosis, treatment and follow-up. Ann Oncol 2016; 27 (suppl 5): v38-v49. DOI: 10.1093/annonc/mdw350

3. Rimaitis K, Pavalkis D. Does epidural anaesthesia and analgesia really improves surgical outcome after colorectal cancer surgery? Acta Chir Iugosl 2006; 53: 85-89

4. Ramachandran SK, Haider N, Saran KA, Mathis M, Kim J, Morris $\mathrm{M}$, et al. Life-threatening critical respiratory events: A retrospective study of postoperative patients found unresponsive during analgesic therapy. J Clin Anesth 2011; 23: 207-213. DOI: $10.1016 /$ j.jclinane.2010.09.003

5. Livingston EH, Passaro EP Jr. Postoperative ileus. Dig Dis Sci 1990; 35: 121-132
6. Guay J, Nishimori M, Kopp SL. Epidural Local Anesthetics Versus Opioid-Based Analgesic Regimens for Postoperative Gastrointestinal Paralysis, Vomiting, and Pain After Abdominal Surgery: A Cochrane Review. Anesth Analg 2016; 123: 15911602. DOI: 10.1213/ANE.0000000000001628

7. Winer AG, Sfakianos JP, Puttanniah VG, Bochner BH. Comparison of perioperative outcomes for epidural versus intravenous patient-controlled analgesia after radical cystectomy. Reg Anesth Pain Med 2015; 40: 239-244. DOI: 10.1097/AAP.0000000000000219

8. Sinatra R. Causes and consequences of inadequate management of acute pain. Pain Med 2010; 11: 1859-1871. DOI: 10.1111/ j.1526-4637.2010.00983.x

9. Cleeland CS. The impact of pain on the patient with cancer. Cancer 1984; 54(11 Suppl): 2635-2641. DOI: 10.1002/1097$0142(19841201) 54: 2+<2635::$ AID-CNCR2820541407> 3.0.CO;2-P

10. Hudcova J, McNicol E, Quah C, Lau J, Carr DB. Patient controlled opioid analgesia versus conventional opioid analgesia for acute postoperative pain. Cochrane Database Syst Rev 2006; (4): CD003348. DOI: 10.1002/14651858.CD003348.pub2

11. Walder B, Schafer M, Henzi I, Tramèr MR. Efficacy and safety of patient-controlled opioid analgesia for acute postoperative pain. A quantitative systematic review. Acta Anaesthesiol Scand 2001; 45: 795-804. DOI: 10.1034/j.1399-6576.2001. 045007795.x

12. Capdevila X, Barthelet Y, Biboulet P, Ryckwaert Y, Rubenovitch J, d'Athis F. Effects of perioperative analgesic technique on the surgical outcome and duration of rehabilitation after major knee surgery. Anesthesiology 1999; 91: 8-15

13. Jain R, Gupta P, Jain V. A comparison of ropivacaine with fentanyl to bupivacaine with fentanyl for post-operative patient controlled epidural analgesia in patients undergone lower abdominal cancer surgery. IAIM 2016; 3: 137-149

14. Kehlet H, Holte K. Effect of postoperative analgesia on surgical outcome. Br J Anaesth 2001; 87: 62-72

15. Mann C, Pouzeratte Y, Boccara G, Peccoux C, Vergne C, Brunat $G$, et al. Comparison of intravenous or epidural patientcontrolled analgesia in the elderly after major abdominal surgery. Anesthesiology 2000; 92: 433-441

16. Rodriguez CS. Pain measurement in the elderly: a review. Pain Manag Nurs 2001; 2: 38-46. DOI: 10.1053/jpmn.2001.23746

17. Breivik H, Borchgrevink PC, Allen SM, Rosseland LA, Romundstad L, Hals EK, et al. Assessment of pain. Br J Anaesth 2008; 101: 17-24. DOI: 10.1093/bja/aen103

18. Krebs EE, Carey TS, Weinberger M. Accuracy of the pain numeric rating scale as a screening test in primary care. J Gen Intern Med 2007; 22: 1453-1458. DOI: 10.1007/s11606-0070321-2

19. Research Randomizer [online]. [place unknown], [publisher unknown]; 2007 [cited 2017 January 11]. Available from: URL: http:/www.randomizer.org

20. Ali M, Winter DC, Hanly AM, O'Hagan C, Keaveny J, Broe P. Prospective, randomized, controlled trial of thoracic epidural or patient-controlled opiate analgesia on perioperative quality of life. Br J Anaesth 2010; 104: 292-297. DOI: 10.1093/bja/ aeq006

21. R Core Team. The R Project for Statistical Computing; R: A Language and Environment for Statistical Computing [Internet]. Vienna, Austria; 2016 [cited 2017 January 08]. Available from: URL: http://www.r-project.org 
22. McAleese P, Odling-Smee W. The effect of complications on length of stay. Ann Surg 1994; 220: 740-744. DOI: 10.1097/ 00000658-199412000-00006

23. Collins TC, Daley J, Henderson WH, Khuri SF. Risk Factors for Prolonged Length of Stay after Major Elective Surgery. Ann Surg 1999; 230: 251-259

24. Moslemi F, Rasooli S, Baybordi A, Golzari SEJ. A Comparison of Patient Controlled Epidural Analgesia with Intravenous Patient Controlled Analgesia for Postoperative Pain Management after Major Gynecologic Oncologic Surgeries: A Randomized Controlled Clinical Trial. Anesth Pain Med 2015; 5(5): e29540. DOI: $10.5812 /$ a apm. 29540

25. Wu CL, Cohen SR, Richman JM, Rowlingson AJ, Courpas GE, Cheung K, et al. Efficacy of postoperative patient-controlled and continuous infusion epidural analgesia versus intravenous patient-controlled analgesia with opioids: a meta-analysis. Anesthesiology 2005; 103: 1079-1088

26. Ferguson SE, Malhotra T, Seshan VE, Levine DA, Sonoda Y, Chi DS, et al. A prospective randomized trial comparing patientcontrolled epidural analgesia to patient-controlled intravenous analgesia on postoperative pain control and recovery after major open gynecologic cancer surgery. Gynecol Oncol 2009; 114: 111-116. DOI: 10.1016/j.ygyno.2009.03.014

27. Steinberg RB, Liu SS, Wu CL, Mackey DC, Grass JA, Ahlén K, et al. Comparison of ropivacaine-fentanyl patient-controlled epidural analgesia with morphine intravenous patient-controlled analgesia for perioperative analgesia and recovery after open colon surgery. J Clin Anesth 2002; 14: 571-577. DOI: 10.1016/ S0952-8180(02)00451-8

28. Kalff JC, Schraut WH, Simmons RL, Bauer AJ. Surgical manipulation of the gut elicits an intestinal muscularis inflammatory response resulting in postsurgical ileus. Ann Surg 1998; 228: $652-663$

29. Marderstein EL, Delaney CP. Management of postoperative ileus: focus on alvimopan. Ther Clin Risk Manag 2008; 4: 965973. DOI: $10.2147 /$ TCRM.S3147

30. Carli F, Trudel JL, Belliveau P. The effect of intraoperative thoracic epidural anesthesia and postoperative analgesia on bowel function after colorectal surgery: a prospective, randomized trial. Dis Colon Rectum 2001; 44: 1083-1089. DOI: 10.1007/ BF02234626
31. Liu SS, Carpenter RL, Mackey DC, Thirlby RC, Rupp SM, Shine $\mathrm{TS}$, et al. Effects of perioperative analgesic technique on rate of recovery after colon surgery. Anesthesiology 1995; 83: 757765

32. Rimaitis K, Marchertienè I, Pavalkis D. Comparison of two different methods of analgesia. Postoperative course after colorectal cancer surgery. Medicina (Kaunas) 2003; 39: 129-137

33. Watcha MF, White PF. Postoperative nausea and vomiting: its etiology, treatment, and prevention. Anesthesiology 1992; 77: 162-184

34. Rao DG, Basavaraj SC. Evaluation of the Efficacy and Safety of Ramosetron versus Ondansetron for prevention of postoperative nausea and vomiting in gynaecological surgery. IJCA 2016; 3: 20-26. DOI: 10.5958/2394-4994.2016.00004.4

35. Martos-Benítez FD, Gutiérrez-Noyola A, Echevarría-Víctores A. Postoperative complications and clinical outcomes among patients undergoing thoracic and gastrointestinal cancer surgery: A prospective cohort study. Rev Bras Ter Intensiva 2016; 28: 40-48. DOI: $10.5935 / 0103-507 X .20160012$

36. Moraca RJ, Sheldon DG, Thirlby RC. The role of epidural anesthesia and analgesia in surgical practice. Ann Surg 2003; 238: 663-673. DOI: 10.1097/01.sla.0000094300.36689.ad

37. Moen V, Dahlgren N, Irestedt L. Severe neurological complications after central neuraxial blockades in Sweden 1990-1999. Anesthesiology 2004; 101: 950-959

38. Ballantyne JC, Carr DB, deFerranti S, Suarez T, Lau J, Chalmers $\mathrm{TC}$, et al. The comparative effects of postoperative analgesic therapies on pulmonary outcome: cumulative meta-analyses of randomized, controlled trials. Anesth Analg 1998; 86: 598612. DOI: $10.1213 / 00000539-199803000-00032$

39. Pöpping DM, Elia N, Marret E, Remy C, Tramčr MR. Protective effects of epidural analgesia on pulmonary complications after abdominal and thoracic surgery: a meta-analysis. Arch Surg 2008; 143: 990-999. DOI: 10.1001/archsurg.143.10.990

40. Holte K, Kehlet H. Epidural analgesia and risk of anastomotic leakage. Reg Anesth Pain Med 2001; 26: 111-117. DOI: 10.1053/ rapm.2001.21241

41. Stelfox HT, Hemmelgarn BR, Bagshaw SM, Gao S, Doig CJ, Nijssen-Jordan C, et al. Intensive care unit bed availability and outcomes for hospitalized patients with sudden clinical deterioration. Arch Intern Med 2012; 172: 467-474. DOI: 10.1001/archinternmed.2011.2315 